ESJ Natural/Life/Medical Sciences

\title{
Associations Between Self-Reported Sleep, Wellbeing and Physical Activity in Irish Adolescents
}

\author{
John Murphy, \\ School of Arts, Education and Movement, Dublin City University Institute \\ of Education \\ Dr Mary Rose Sweeney, \\ School of Nursing, Psychotherapy and Community Health, Dublin City \\ University \\ Dr Anna Donnla O’Hagan, \\ School of Health and Human Performance, Dublin City University \\ Dr Bronagh McGrane, \\ School of Arts, Education and Movement, Dublin City University Institute \\ of Education
}

Doi:10.19044/esj.2022.v18n8p1

Submitted: 20 December 2021

Accepted: 01 February 2022

Published: 28 February 2022
Copyright 2022 Author(s)

Under Creative Commons BY-NC-ND 4.0 OPEN ACCESS

Cite As:

Murphy SJ, Sweeney MR, O’Hagan AD,\& McGrane B.,(2022). Associations Between SelfReported Sleep, Wellbeing and Physical Activity in Irish Adolescents European Scientific Journal, ESJ, 18 (8), 1.

https://doi.org/10.19044/esj.2022.v18n8p1

\section{Abstract}

Growing evidence suggests sleep plays an important role in the development of healthy adolescents, with increased interest in the associations between sleep and mental health. Higher duration and quality of sleep has been suggested as a mechanism for increased wellbeing in adolescents. Cross sectional data was collected from 5,661 Irish adolescents. 55\% of Irish adolescents reported meeting the guidelines for adolescents of 8-10 hours per night. This was found to decrease with age. Higher duration and quality of sleep was positively associated with wellbeing and negatively associated with symptoms of anxiety and depression. A higher frequency of physical activity was associated with longer duration and higher quality of sleep. 9-10 hours of sleep was associated with the highest levels of wellbeing and lowest symptoms of anxiety and depression. The relationship between physical activity and increased wellbeing may be impacted by physical activity leading to higher 
durations and quality of sleep. Higher frequencies of physical activity may increase sleep quality and quantity thereby improving markers of mental health in adolescents.

Keywords: Sleep Duration; Sleep Latency; Sleep Efficiency; Health Behaviour

\section{Introduction}

Growing Evidence Suggests That Sleep Plays A Crucial Role In The Development Of Healthy Adolescents (12-19 Years), With A Particular Emphasis On The Regulation Of Important Daily Cognitive Functions (Such As Attention, Vigilance, Problem-Solving, Etc), Mood And Emotional Wellbeing (Dahl \& Lewin, 2002). Many Epidemiological And Laboratory Studies Also Provide Preliminary Evidence For The Potential Role Of Sleep Curtailment In Adolescents And Children With Obesity (Litsfeldt, Ward, Hagell \& Garmy, 2020). The Role Of Sleep Is More Complicated In The Adolescent Population Due To Higher Sleep Needs Coupled With The Growth- And Lifestyle-Related Sleep Changes, Such As Social Lives And Shifts In Circadian Rhythms, Seen At This Developmental Stage Of Life (National Sleep Foundation, 2019). The Trend Over Time Has Been Towards Insufficient Sleep In The Younger Population, Which May Be Further Increasing The Burden Of Short Sleep-Mediated Outcomes Including Both Physical And Mental Ill Health (Magee, Caputi \& Iverson, 2014). The US National Sleep Foundation's Recommended Duration Of Sleep For Adolescents Is 8-10 Hours Per Night (Hirshkowitz Et Al., 2015).

Research Focusing On Sleep Loss Or Short-Sleep Duration Has Found Connections To Both Cognitive And Emotive Issues Such As Impaired Capacity To Learn (Gomez, Newman-Smith, Breslin \& Bootzin, 2011); Decreased Academic Performance (Dewald, Meijer, Oort, Kerkhof \& Bogels, 2010); And Symptoms Of Depression (Gangswich Et Al., 2010). Other Research That Focuses On Depression And Depressive Symptoms In Children And Adolescents Found That Sleep Disorders Are Common Although Disordered Sleep Can Both Stem From, And Cause, Elevated Symptoms Of Depression (Liu Et Al., 2007) With The Majority Of Studies Investigating The Specific Relationship Between Short Sleep Duration And Depression Focusing On Adolescents (Giannotti, Cortesi, Sebastiani \& Ottaviano, 2002). One Of The Most Influential Investigations Found That Adolescents With Parent Set Bedtimes Of Midnight Or Later Were 24\% More Likely To Suffer From Depression And 20\% More Likely To Have Suicidal Ideation Than Adolescents With Parent Set Bedtimes Of 10:00pm Or Earlier (Gangswich Et Al., 2010). The Bi-Directional Relationship, Where Disordered Sleeping Impacts Mental Health Outcomes And Symptoms Of Depression And Anxiety 
Impact Sleep Has Also Been Demonstrated In Non-Clinical Child And Adolescent Populations (Muiris, Van Der Pennen, Sigmond \& Mayer, 2008). 40\% Of Irish Adolescents Reported Elevated Symptoms Of Anxiety And Depression (Murphy, Sweeney \& Mcgrane, 2020) Pre Covid-19 While 46\% Reported Elevated Symptoms During Restrictions (Murphy, Mcgrane \& Sweeney, 2021) Although Higher Levels Of Physical Activity Were Associated With Lower Symptoms Of Both. Lubans Et Al., (2016) Proposed A Number Of Mechanisms That Sought To Explain The Impact Of Physical Activity On Mental Health And Wellbeing, One Of Which Is Based On Sleep, Where Increased Quality And Duration Of Sleep Is Positively Associated With Increased Wellbeing. A Recent Meta-Analysis Of The Effects Of Physical Activity On Sleep Found That Bouts Of Acute Exercise Had Benefits On Sleep Duration And Sleep Quality While Regular Exercise, Of Any Intensity, Had Beneficial Effects On Sleep Duration And Efficiency (Kredlow, Capozzoli, Hearon, Calkins \& Otto, 2015). An Investigation Of Physical Activity And Sleeping Patterns Also Found That Adolescents Who Engaged In 60 Minutes Or More Of Physical Activity Per Day Had Increased Odds Of Meeting Sleep Recommendations Than Those Who Did Not (Foti, Eaton, Lowry \& Mckinight-Ely, 2011). Another Cross-Sectional Examination Of US Adolescents Found That 66\% Of Boys And 75\% Of Girls Do Not Meet Physical Activity Recommendations Which Was Associated With Lower Odds Of Achieving Adequate Sleep (Kenney \& Gortmaker, 2017). Similar Findings Were Found In European Adolescents As Insufficient And Poor Sleep Patterns Are Common Throughout The European Union (Gariepy Et Al., 2020). Adolescents Achieving The Recommended Duration Of Sleep Range From 32\% In Some Countries (Poland) To 86\% In Others (Flemish Belgium) With No Specific Data Collected In Irish Adolescents. No Previous Studies Have Explored The Association Between Duration Of Sleep And Symptoms Of Mental Health Or Physical Activity In Irish Adolescents.

The Aim Of This Study Was To Investigate Sleep Duration, By Year And Gender, Among Adolescents In Ireland. This Research Will Also Examine Associations Between Sleep, Physical Activity, And Mental Health Outcomes.

\section{Method}

Cross Sectional Data Were Drawn From The Physical Activity And Wellbeing Study (PAWS) (Murphy, Sweeney \& Mcgrane, 2020). Data Collection Took Place During September And October 2019. The Study Was Approved By The DCU Ethics Committee (DCUREC/2019/107) Prior To Any Data Being Collected. 144 Schools Initially Registered Interest In Taking Part. 65 Schools Were Unable To Participate Fully Due To Either; Commitments To Other Research; Availability Of Time; Or Lack Of Principal 
Consent. The Remaining 79 Schools Who Registered Interest Represent 11\% Of The Post-Primary Schools In Ireland. 5661 Participants Were Recruited From These 79 Schools Throughout The Republic Of Ireland With A Minimum Of One School From Each Of The 26 Counties In Ireland. The Number Of Student Responses In Each School Ranged From 24 To 232.

\section{Data Collection}

Written Consent From Each School's Principal Was Sought Prior To The Distribution Of Questionnaires. Parental Consent Forms And Plain Language Statements Were Given To All Students Prior To The Questionnaire Being Issued. Students Were Administered A Self-Report Questionnaire, Which Included Well-Established And Validated Instruments To Assess Sleep, Physical Activity, Wellbeing, And Symptoms Of Depression And Anxiety. Participants Were Informed That Their Responses Would Be Treated In Strictest Confidence And That All Responses Were Entirely Anonymous. They Were Encouraged To Take Time, Reflect On Their Answers, And To Be As Honest As Possible. All Questionnaires Were Administered In School Through An Online Form And Could Be Completed Via Desktop Computer, Laptop, Tablet Or Mobile Phone. An Option To Contact The National Education Psychologists Service (NEPS) Was Offered To Participants After Completion Of The Questionnaire. The Means Of Administering The Questionnaire Was At The Discretion Of Each Participating School.

\section{Mental Health}

Depressive Symptoms: Severity Of Depressive Symptoms Was Measured Via The Beck Depression Inventory (BDI). Items Of This Instrument Assess Specific Symptoms Of Depression Experienced Over The Preceding Two Weeks. Each Question Was Scored From 0 To 3, Indicating The Severity Of The Symptom, With Total Scores Ranging From 0 To 60. Cronbach's Alpha In Our Sample Was 0.94. The Reliability And Validity Of The BDI Have Been Confirmed In Clinical And Community Samples Of Adolescents.

Anxiety Symptoms: Symptoms Of Anxiety Were Assessed Using The Beck Anxiety Inventory (BAI), A 21-Item Self-Report Questionnaire. Responses To Each Item Range From 0 To 3 With Scores Ranging From 0 To 63 With Higher Scores Indicating Increased Levels Of Anxiety. Cronbach's Alpha In Our Sample Was 0.93.

Wellbeing: Wellbeing Was Assessed Using The Warwick Edinburgh Mental Wellbeing Scale (WEMWS), Which Measures Positive Psychological Wellbeing Through A 14 Item Self-Report Questionnaire. Responses To Each Item Range From 1 To 5 With Overall Scores Ranging From 14 To 70 Where 
70 Represents The Best Possible Level Of Wellbeing. Cronbach's Alpha In Our Sample Was 0.83, Indicating Good Internal Reliability.

Sleep

Sleep Was Measured Using An Adapted Form Of The Pittsburgh Sleep Quality Index (Buysse, Reynolds, Monk, Berman \& Kupfer, 1989) Which Has Been Validated For Use In Adolescents (Raniti, Waloszek, Schwartz, Allen \& Trinder, 2018). Participants Were Asked To Report How Many Hours They Spent Asleep On A Typical School Night And To Rate Their Quality Of Sleep As Either "Very Good”, “Fairly Good”, "Fairly Bad” Or "Very Bad”.

\section{Physical Activity}

Habitual Physical Activity Was Assessed Via A Modified Version Of The Take PART Questionnaire By Measuring The Number Of Days During The Past 14 That Participants Had Accumulated 60 Minutes Of Moderate-ToVigorous Physical Activity (MVPA)). The Survey Item Assessing Physical Activity Was As Follows: "During A Typical 2-Week Period, On How Many Days Were You Physically Active For A Total Of At Least 60 Minutes? For Each Day, Add Up All The Time You Spent In Physical Activity Like Walking, Riding A Bicycle Etc. Count Up The Days With At Least 60 Minutes Of Physical Activity In A Typical 2-Week Period.” Responses Ranged From 0 To 14 Days.

Based On Their Reported Frequency Of Physical Activity, Participants Were Categorised As Least Active (60 Minutes Or More Of Activity On 0-3 Days In The Past 14), Somewhat Active (60 Minutes Or More Of Activity On 4-7 Days In Past 14), Or Most Active (60 Minutes Or More Of Activity On 8-14 Days Of The Past 14. A Further Sub-Group Was Also Created Who Reported Meeting The Daily Physical Activity Guidelines On All 14 Days In A Typical 2-Week Period (Sufficiently Active According To WHO Guidelines).

\section{Statistical Analyses}

To Examine The Associations Between Self-Reported Hours Of Sleep And Mental Health Variables A Mixed Linear Regression Model With Fixed Effects For Gender And Physical Activity, And Random Effects For Year Was Fitted. The Coefficients From This Model Were Used To Estimate Curves Illustrating Associations Between Subjective Sleep And Each Of The Mental Health Measures (Figure 2). Post-Hoc Between-Group Comparisons Were Carried Out Using Tukey's HSD And Bonferroni Correction To Account For Multiple Testing. Analyses Were Conducted In R (R Core Team, 2014) And Figures Were Produced Using The Package Ggplot2 (Wickham, 2009). 


\section{Results}

\section{Participant Characteristics}

In Total, 5661 Adolescents Participated In The Questionnaire. 3247 (57\%) Females, 2386 (42\%) Males And 28 (0.5\%) Who Identified As Neither Female Nor Male. Transition Year Had The Most Participants $(\mathrm{N}=1411$, $25 \%)$ Followed By $3^{\text {rd }}$ Year $(\mathrm{N}=1011,18 \%), 5^{\text {th }}$ Year $(\mathrm{N}=983,17 \%), 2^{\text {nd }}$ Year $(\mathrm{N}=894,16 \%), 1^{\text {st }}$ Year $(\mathrm{N}=872,15 \%)$ And The Least Participants From $6^{\text {th }}$ Year $(\mathrm{N}=490,9 \%)$. Ages Ranged From 11 To 20 Years. The Mean Age Of The Sample Was $14.8(\mathrm{Sd}=1.5)$.

Higher Percentage Of Participants Met The Guidelines Of 8-10 Hours Of Sleep Per Night In Younger Year Groups And This Was Found To Decline As Adolescents Progressed Through School, With The Exception Of Males In Transition Year. A Higher Percentage Of Males Were Also Found To Have Meet Sleep Duration Guidelines In All Year Groups With The Exception Of $6^{\text {th }}$ Year.

Table 1: Percentage of males and females in each category of sleep

\begin{tabular}{|c|c|c|}
\hline Gender & Hours Of Sleep & Percent \\
\hline Female & \multirow{2}{*}{$<5$ Hours } & $2 \%$ \\
\hline Male & & $3 \%$ \\
\hline Female & \multirow{2}{*}{$5-6$ Hours } & $16 \%$ \\
\hline Male & & $12 \%$ \\
\hline Female & \multirow{2}{*}{$6-8$ Hours } & $28 \%$ \\
\hline Male & & $25 \%$ \\
\hline Female & \multirow{2}{*}{8 - 10 Hours } & $53 \%$ \\
\hline Male & & $58 \%$ \\
\hline Female & \multirow{2}{*}{$>10$ Hours } & $1 \%$ \\
\hline Male & & $2 \%$ \\
\hline
\end{tabular}

Table 1 Shows The Percentage Of Males And Females In Each Category Of Sleep. 53\% Of Females And 58\% Of Males Met The Guideline Of 8-10 Hours Per Night. More Females Than Males Were Found To Sleep 5 To 6 (16\% V 12\%) And 6 To 8 Hours Per Night (28\% V 25\%) Respectively.

Sleep \& Psychological Variables

Anxiety: One-Way ANOVA Showed That Participants Who Reported 8-10 Hours Of Sleep Had Significantly Lower $(\mathrm{P}<0.001)$ Symptoms Of Anxiety Than All Sub-Groups Who Reported Less Than 8 Hours Of Sleep (Table 2). One-Way ANOVA Found Significant Differences Between SelfReported Quality Of Sleep And Symptoms Of Anxiety After Bonferroni Correction. Those Who Reported Very Good Sleep Had Significantly Lower Symptoms Of Anxiety Than Those Who Reported Fairly Good Sleep (P = 0.006), Fairly Bad Sleep $(\mathrm{P}=0.003)$ And Very Bad Sleep $(\mathrm{P}=0.002)$. Those Who Reported Fairly Good Sleep Had Significantly Lower Symptoms Of 
Anxiety Than Those Who Reported Fairly Bad Sleep ( $\mathrm{P}=0.003)$ And Those Who Reported Very Bad Sleep ( $\mathrm{P}=0.003)$. Those Who Reported Fairly Bad Sleep Had Significantly Lower Symptoms Of Anxiety Than Those Who Reported Very Bad Sleep $(\mathrm{P}=0.002)$.

Table 2: Wellbeing, anxiety and depression by sleep category subgroup

\begin{tabular}{|c|c|c|c|}
\hline $\begin{array}{c}\text { Sleep } \\
\text { Subgroup }\end{array}$ & $\begin{array}{c}\text { Wellbeing } \\
\text { Mean (SD) }\end{array}$ & $\begin{array}{c}\text { Depression } \\
\text { Mean (SD) }\end{array}$ & $\begin{array}{c}\text { Anxiety } \\
\text { Mean (SD) }\end{array}$ \\
\hline$<\mathbf{5}$ Hours & $36.8(12.1)^{*}$ & $28.4(11.9)^{* *}$ & $32.4(11.7)^{* *}$ \\
\hline $\mathbf{5}$ - 6 Hours & $41.7(9.7)^{*}$ & $18.5(9.5)^{* *}$ & $23.7(10.7)^{* *}$ \\
$\mathbf{6}-\mathbf{8}$ Hours & $45.9(8.6)^{*}$ & $11.7(7.4)^{* *}$ & $17.3(9.1)^{* *}$ \\
\hline $\mathbf{8 - 1 0}$ Hours & $49.4(8.2)$ & $7.6(6.3)$ & $13.7(8.3)$ \\
\hline$>\mathbf{1 0}$ Hours & $48.4(8.8)$ & $8.9(7.4)$ & $13.5(10.1)$ \\
\hline
\end{tabular}

*Significantly lower wellbeing than $8-10$ hours of sleep per night $(\mathrm{p}<0.001)$

**Significantly higher symptoms of depression/anxiety than $8-10$ hours of sleep per night $(\mathrm{p}<0.001)$

Depression: Participants Who Reported 8-10 Hours Of Sleep Had Significantly Lower Symptoms Of Depression $(\mathrm{P}<0.001)$ Than All SubGroups Who Reported Less Than 8 Hours Of Sleep (Table 2). One-Way ANOVA Found Significant Differences Between Self-Reported Quality Of Sleep And Symptoms Of Depression After Bonferroni Correction. Those Who Reported Very Good Sleep Had Significantly Lower Symptoms Of Depression Than Those Who Reported Fairly Good Sleep ( $\mathrm{P}=0.002)$, Fairly Bad Sleep ( $\mathrm{P}=0.007)$ And Very Bad Sleep $(\mathrm{P}=0.003)$. Those Who Reported Fairly Good Sleep Had Significantly Lower Symptoms Of Depression Than Those Who Reported Fairly Bad Sleep $(\mathrm{P}=0.001)$ And Those Who Reported Very Bad Sleep $(\mathrm{P}=0.001)$. Those Who Reported Fairly Bad Sleep Had Significantly Lower Symptoms Of Depression Than Those Who Reported Very Bad Sleep $(\mathrm{P}=0.001)$.

Table 3: Percentage of self-reported quality of sleep by gender

\begin{tabular}{|c|c|c|c|c|c|}
\hline $\begin{array}{l}\text { Quality Of } \\
\text { Sleep }\end{array}$ & Gender & $\begin{array}{l}\text { Percentage of } \\
\text { Gender }\end{array}$ & $\begin{array}{l}\text { Wellbeing } \\
\text { Mean (SD) }\end{array}$ & $\begin{array}{l}\text { Depression } \\
\text { Mean (SD) }\end{array}$ & $\begin{array}{c}\text { Anxiety } \\
\text { Mean (SD) }\end{array}$ \\
\hline \multirow[t]{2}{*}{ Very Good } & Female & $19.9 \%$ & $51(8.8)$ & $6(3.6)$ & $12(10.5)$ \\
\hline & Male & $27.4 \%$ & $53(8.5)$ & $4(3.5)$ & $9(9.2)$ \\
\hline \multirow{2}{*}{$\begin{array}{l}\text { Fairly } \\
\text { Good }\end{array}$} & Female & $51.8 \%$ & 47 (7.8) & $11(4.4)$ & 18 (11.8) \\
\hline & Male & $51.3 \%$ & $50(7.7)$ & $7(4.1)$ & 12 (9.7) \\
\hline \multirow[t]{2}{*}{ Fairly Bad } & Female & $22.1 \%$ & $40(8.6)$ & 20 (5.9) & 26 (13.6) \\
\hline & Male & $16.3 \%$ & 45 (8.3) & 13 (4.9) & 17 (11.6) \\
\hline
\end{tabular}




\begin{tabular}{|c|c|c|c|c|c|} 
Very Bad & Female & $6.1 \%$ & $37(10.1)$ & $28(7.4)$ & $32(14.2)$ \\
& Male & $4.8 \%$ & $44(10.7)$ & $21(7.7)$ & $24(15.2)$ \\
\hline
\end{tabular}

Wellbeing: Participants Who Reported 8 To 10 Hours Of Sleep Had Significantly Greater Wellbeing $(\mathrm{P}<0.001)$ Than All Sub-Groups Who Reported Less Than 8 Hours Of Sleep (Table 2). One-Way ANOVA Found Significant Differences Between Self-Reported Quality Of Sleep And Wellbeing After Bonferroni Correction. Those Who Reported Very Good Sleep Had Significantly Higher Wellbeing Than Those Who Reported Fairly Good Sleep ( $\mathrm{P}=0.004)$, Fairly Bad Sleep $(\mathrm{P}=0.004)$ And Very Bad Sleep ( $=0.001)$. Those Who Reported Fairly Good Sleep Had Significantly Higher Wellbeing Than Those Who Reported Fairly Bad Sleep $(\mathrm{P}=0.003)$ And Those Who Reported Very Bad Sleep ( $\mathrm{P}=0.007)$. Those Who Reported Fairly Bad Sleep Had Significantly Higher Wellbeing Than Those Who Reported Very Bad Sleep $(\mathrm{P}=0.007)$. 


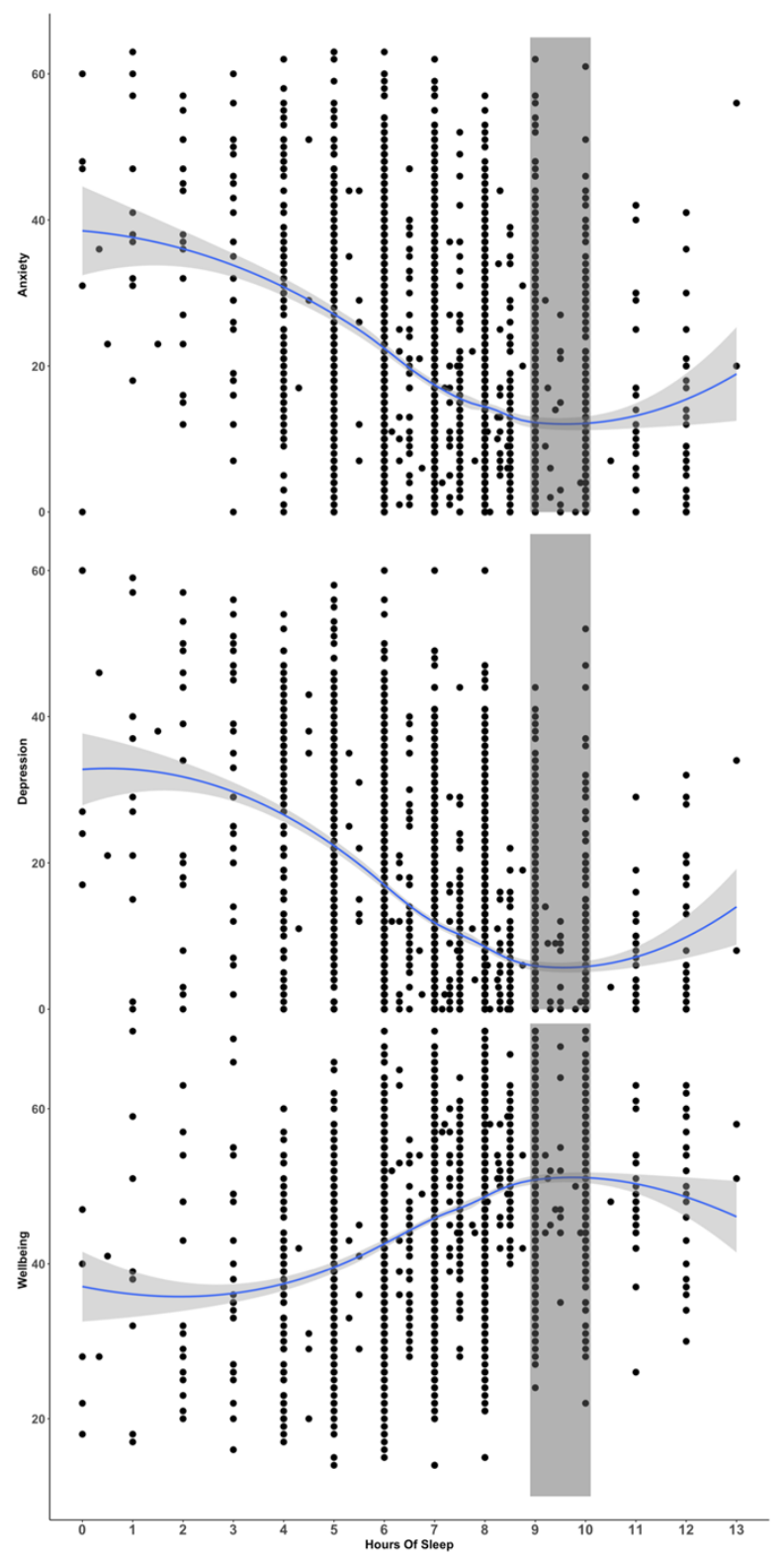

\section{Associations Between Self-Reported Hours Of Sleep With Symptoms Of Anxiety, Depression And Wellbeing:}

A Curvilinear Relationship Was Observed Between Self-Reported Hours Of Sleep And All Three Psychological Outcomes And Can Be Seen In Figure 2. Participants Who Reported 9 To 10 Hours Of Sleep Are Associated With The Lowest Symptoms Of Anxiety And Depression, And Highest Levels Of Wellbeing. Linear Mixed-Models With Fixed Effects For Gender, Year And Physical Activity Observed That Hours Of Sleep Had A Significant 
Effect On Depression, Anxiety And Wellbeing Even When Controlling For Gender, Year And Physical Activity. Outputs Can Be Seen In Table 4.

Table 4: Model Outputs

\begin{tabular}{|c|c|c|c|}
\hline Predictors & Estimates & Confidence Intervals & $\mathbf{p}$ \\
\hline \multicolumn{4}{|c|}{ Depression } \\
\hline (Intercept) & 15.92 & $15.30-16.53$ & $<0.001$ \\
\hline Sleep Duration & 0.00 & $0.00-0.00$ & $<0.001$ \\
\hline Gender [Male] & -4.11 & $-4.68--3.55$ & $<0.001$ \\
\hline Physical Activity & -0.45 & $-0.53--0.38$ & $<0.001$ \\
\hline $\mathrm{R}^{2} / \mathrm{R}^{2}$ adjusted & & & \\
\hline \multicolumn{4}{|l|}{$\mathrm{R}^{2} / \mathrm{R}^{2}$ adjusted } \\
\hline (Intercept) & 22.61 & $21.98-23.32$ & $<0.001$ \\
\hline Sleep Duration & 0.00 & $0.00-0.00$ & $<0.001$ \\
\hline Gender [Male] & -6.10 & $-6.76--5.44$ & $<0.001$ \\
\hline Physical Activity & -0.47 & $-0.56--0.38$ & $<0.001$ \\
\hline $\mathrm{R}^{2} / \mathrm{R}^{2}$ adjusted & & & \\
\hline \multicolumn{4}{|c|}{$\begin{array}{l}0.089 / 0.089 \\
\text { Wellbeing }\end{array}$} \\
\hline (Intercept) & 41.77 & $41.26-42.28$ & $<0.001$ \\
\hline Sleep Duration & -0.00 & $-0.00--0.00$ & 0.002 \\
\hline Gender [Male] & 3.24 & $2.77-3.72$ & $<0.001$ \\
\hline Physical Activity & 0.54 & $0.47-0.60$ & $<0.001$ \\
\hline $\mathrm{R}^{2} / \mathrm{R}^{2}$ adjusted & \multicolumn{3}{|c|}{$0.093 / 0.093$} \\
\hline
\end{tabular}

\section{Self-Reported Sleep And Physical Activity}

In Our Sample, 63\% Of Males And 63.7\% Of Females Who Met Physical Activity Recommendations Also Met The Recommended 8-10 Hours Of Sleep Per Night And Can Be Seen In Table 5. 57.5\% Of Males And 51.9\% Of Females Who Did Not Meet Physical Activity Recommendations Met Recommendations For Good Sleep Hygiene For Adolescents. 62.3\% Of Males And 58.8\% Of Females In The Most Active Group Met Recommendations For Good Sleep Hygiene. 57.4\% Of Males And 52.2\% Of Females In The Somewhat Active Group Met Recommendations For Good Sleep Hygiene. 41\% Of Males And 42.6\% Of Females In The Least Active Group Met Recommendations For Good Sleep Hygiene.

Table 5: Percentage of males and females achieving 8-10 hours of sleep by physical activity sub-category

\begin{tabular}{|l|c|c|}
\hline Physical Activity & Female & Male \\
\hline Meeting PA Guidelines & & \\
Not Meeting PA & $53.7 \%$ & $63.0 \%$ \\
Guidelines & & $57.5 \%$ \\
\hline
\end{tabular}




\begin{tabular}{|l|c|c|}
\hline $\begin{array}{l}\text { Least Active } \\
(0-3 \text { days })\end{array}$ & $42.6 \%$ & $41.0 \%$ \\
$\begin{array}{l}\text { Somewhat Active } \\
(4-7 \text { days })\end{array}$ & $52.2 \%$ & $57.4 \%$ \\
$\begin{array}{l}\text { Most Active } \\
(8-14 \text { days })\end{array}$ & $58.8 \%$ & $62.3 \%$ \\
\hline
\end{tabular}

Self-Reported Sleep Quality Varied Across Physical Activity Sub-Categories And Are Detailed In Table 6. 36\% Of Those Who Met The Physical Activity Recommendations Rated Sleep As Very Good, 44.5\% Rated Sleep As Fairly Good, 13.9\% Rated Sleep As Fairly Bad, And 5.6\% Rated Sleep As Very Bad. 22\% Of Those Who Did Not Meet The Physical Activity Recommendations Rated Sleep As Very Good, 52.2\% Rated Sleep As Fairly Good, 20.2\% Rated Sleep As Fairly Bad, And 5.5\% Rated Sleep As Very Bad.

Table 6: Self-reported quality of sleep by physical activity sub-category

\begin{tabular}{|l|c|c|c|c|}
\hline Physical & Very Good & Fairly Good & Fairly Bad & Very Bad \\
Subgrivity & & $44.5 \%$ & $13.9 \%$ & $5.6 \%$ \\
\hline $\begin{array}{l}\text { Meeting PA } \\
\text { Guidelines } \\
\text { Not Meeting } \\
\text { PA }\end{array}$ & $22.0 \%$ & $52.2 \%$ & $20.2 \%$ & $5.5 \%$ \\
Guidelines & $36.0 \%$ & $17.6 \%$ & $22.5 \%$ & $26.3 \%$ \\
\hline $\begin{array}{l}\text { Least Active } \\
\text { (0-3 days) }\end{array}$ & $14.0 \%$ & $37.0 \%$ & $39.2 \%$ & $35.9 \%$ \\
$\begin{array}{l}\text { Somewhat } \\
\text { Active } \\
\text { (4-7 days) } \\
\text { Most Active } \\
\text { (8-14 days) }\end{array}$ & $34.6 \%$ & $45.3 \%$ & $38.2 \%$ & $37.8 \%$ \\
\hline
\end{tabular}

\section{Discussion}

This Cross-Sectional Study Sought To Identify The Percentage Of Male And Female Irish Adolescents Who Met The US National Sleep Foundation's Recommendations Of "8-10 Hours Per Night" (Hirshkowitz Et Al., 2015). The Authors Also Sought To Explore The Impact That SelfReported Sleep Has On Mental Health Outcomes, Particularly Wellbeing And Symptoms Of Anxiety And Depression, And How Levels Of Physical Activity 
May Contribute To This. On Average, 55.5\% Of Irish Adolescents Achieved The Recommended Amount With More Males (58\%) Reporting 8-10 Hours Of Sleep Than Females (53\%) As Can Be Seen In Table 1. This Is Slightly More Than A Previous Investigation Of Sleep In Irish Adolescents Who Found That 52\% Of Males Achieved 8-10 Hours Compared To 44\% Of Females (Dooley, O’Connor, Fitzgerald \& O’Reilly, 2019). First Years (75\%) And Second Years (60.5\%) Were More Likely To Report 8-10 Hours Of Sleep Per Night, While Adolescents In Senior Cycle (Transition, $5^{\text {th }}$ Or $6^{\text {th }}$ Year) Were Less Likely To Report 8-10 Hours Per Night With The Largest Reduction In Females From Third Year To Transition Year And The Largest In Males From Transition Year To Fifth Year. This Is Consistent With Dooley Et Al's (2019) Previous Investigation Who Also Found That Sixth Year Had The Lowest Percentage Of Students Meeting The Recommendations For Sleep Duration. Of The Adolescents Surveyed, 26.5\% Reported Getting 6-8 Hours Of Sleep While 14\% Reported 5-6 Hours. A Further 3\% Reported Less Than 5 Hours Or Greater Than 10 Hours. This Is Inconsistent With Dooley Et Al (2019) Who Reported 46\% Getting 6-7 Hours Per Night And Only 7\% Getting 0-5 Hours, Which Suggests A Twofold Increase In The Amount Of Irish Adolescents Who Are Well Below The Recommendations For Adequate Duration Of Sleep.

While Consistent With Previous Research In Ireland, A Larger Percentage Of Males Meeting Sleep Recommendations Is In Contrast To International Research Who Found That Males Sleep Less And Go To Bed Later Than Females (Keyes, Maslowsky, Hamilton \& Schulenberg, 2015). Irish Adolescents Are Slightly Above The Norm In Terms Of Adequate Sleep But Still Below The 86\% Of Flemish Belgian Adolescents Who Sleep 8-10 Hours Per Night, Although They Are Well Ahead Of Other Countries Such As Poland (32\%), Greece (35\%), And Slovenia (38\%) As Was Reported By The Health Behaviour In School-Aged Children's Study (Gariepy Et Al., 2020). Sleep Patterns Changing With Age Is In Line With Previous Studies (Gradisar, Gardner \& Dohnt, 2011; Olds Et Al., 2010). Older Adolescents Have Consistently Been Found To Sleep Less, Go To Bed Later And Experience Greater Social Jetlag Than Younger Adolescents (Gariepy Et Al., 2020). These Changes Reflect The Normative Developmental Course Of The Circadian Clock, Which Shifts Toward Evening-Ness Around Puberty, Peaks At Around Age 16 Years, And Shifts Back In Early Adulthood (Randler, Fabl \& Kalb, 2017). Increased Schoolwork Along With Greater Use Of Social Media And Electronic Devices Add To The Biological Tendency Of Older Adolescents To Fall Asleep At A Later Time. Older Adolescents Are Also Afforded Greater Autonomy By Their Parents In Terms Of Selecting Sleep Times (Pyper, Harrington \& Manson, 2017). It Must Be Noted That Sleep Patterns Were Examined Across Year Group And Not Pubertal Development. 
Changes In Adolescent Sleep Patterns Have Been Attributed To Hormonal And Physiological Changes Related To Puberty More Than Age (Sadeh, Dahl, Shahar \& Rosenblat-Stein, 2009) And So Could Be Explored Further In Future Research.

As Reported By Murphy, Sweeney And Mcgrane (2020), 4 Out Of 10 Irish Adolescents Suffered From Elevated Symptoms Of Anxiety And Depression Prior To The Onset Of Covid-19 And This Had Risen To 46\% During Restrictions (Murphy Et Al., 2021). The Lowest Symptoms Of Anxiety And Depression Found In This Sample Were In Adolescents Who Reported Adequate Sleep, With Incremental Increases In Symptoms As Sleep Decreased. This Inverse Association Between Sleep And Mental Ill-Health Has Also Been Found In Objective Measures Of Sleep Such As Polysomnography (Moore, Bardwell, Ancoli-Israel \& Dimsdale, 2001). As Can Be Seen In Figure 2, 9-10 Hours Of Sleep Appears To Have The Strongest Association With Mental Wellbeing And Reduced Symptoms Of Anxiety And Depression. Prospective Studies Have Previously Demonstrated That Sleep Problems And/Or Sleep Deprivation Increase The Risk For Subsequent Mental/Emotional Dysfunction In Adolescents (Gregory \& O’Connor, 2002) With Shorter Sleep Increasing The Risk For Depressive Symptoms And Low Self-Esteem Both Concurrently And Over Time (Fredriksen, Rhodes, Reddy \& Way, 2004). Studies Looking At The Associations Between Sleep And Psychosocial Outcomes Have Largely Focused On Sleep Restriction And Adolescents With Sleep Problems. One Such Study, Which Examined Elements Of Psychological And Social Functioning Such As Self-Esteem, Depression, Perceived Mental Health, Life Satisfaction, Relations With Parents And Social Support Found That Baseline Insomnia Increased The Risk For All Subsequent Psychosocial Outcomes In A Dose Response Manner (Roberts Et Al., 2009). These Associations Were Maintained For Self-Esteem, Depression And Social Support Even After Adjusting For Age, Gender, Parental Education And Concurrent Insomnia At Follow Up With Severe Insomnia Increasing All Risks By Nearly Twofold. Low Life Satisfaction And Low Levels Of Perceived Mental Health Have Consistently Been Found In Multivariate Analyses (Shochat, Cohen-Zion \& Tzischinsky, 2014). Temporal Associations Between Inadequate Sleep And Mental Ill-Health Were Explored Through A Series Of Retrospective Interviews With Over 1000 Japanese Adolescents (Kaneita Et Al., 2009). Over 50\% Of Adolescents With Insomnia Had A Comorbid Psychiatric Disorder With Anxiety Increasing The Risk For Insomnia, Whereas Insomnia Increased The Risk For Depression. This Suggests A Bi-Directional Relationship Between Inadequate Sleep And Mental Ill-Health Which Was Previously Suggested As A Possible Mechanism By Lubans Et Al (2016), In Particular How Participation In Physical Activity May Improve Sleep Duration, Sleep Efficiency (Stone, 
Stevens \& Faulkner, 2013), Sleep Onset Latency (Lang Et Al., 2013) And Reduced Sleepiness (Gaina Et Al., 2007). Physical Activity Has Also Been Shown To Positively Influence Self-Regulation And Coping Skills That Have Subsequent Implications For Mental Health (Lubans Et Al., 2016).

The Associations Between Self-Reported Sleep Quantity And Symptoms Of Anxiety And Depression Appear To Mirror The Associations With Wellbeing. 9-10 Hours Also Seemed To Be The "Sweet-Spot" For Our Sample Of Adolescents. Research Investigating Positive Psychological States And Sleep Has Increased Alongside The Growth Of Positive Psychology As A Construct In Its Own Right. One Such Investigation, Found That Aspects Of Eudaimonic Wellbeing, Including Purpose In Life, Environmental Mastery, And Positive Relationships, Were Positively Associated With Good Sleep In A Cohort Of Older Adults (Ryff, Singer \& Dienberg, 2004). The Authors Observed That The Environmental Mastery Component Of Eudaimonic Wellbeing Was Positively Associated With Sleep Duration And The Amount Of Rapid Eye Movement (REM) Sleep, And Negatively With Delay To The First Onset Of REM. Steptoe Et Al (2008) Found That Positive Affect And Eudaimonic Wellbeing Were Associated With Fewer Sleep Problems Independently Of Age, Gender, Household Income, Employment Status And Self-Rated Health. The Causal Influence Of Sleep On Wellbeing, Or Vice Versa, Is Unclear From The Current Study. Steptoe Et Al (2008) Found That Sleep Problems Were Commonly Reported By Participants Experiencing High Financial Strain, High Psychological Distress, And More Negative Social Interactions, All Of Which Have A Negative Impact On Wellbeing. They Suggest That Happier Individuals, With A Greater Sense Of Purpose And Positive Orientation, May Be Protected In Part From The Adverse Impact Of Stress And Adversity, Therefore Less Likely To Suffer From Sleep Disturbances. It Is Also Likely That Poor Sleep Both Engenders Lower Positive Affect And Reduced Eudaimonic Wellbeing, And That Positive Psychological States Lead To Better Sleep. This Has Been Reinforced By Recent Findings From A Web-Based Survey Involving 1165 Participants That Suggests People Who Sleep Poorly Are More Likely To Report Negative Emotions Than Persons Who Sleep Well And That Worse-Than-Usual Sleep Is Followed By More Negative Emotions The Day After (Narmandakh, Oldehinkel, Masselink, De Jonge \& Roest, 2021).

Accumulating Evidence Suggests A Number Of Health Benefits For Adolescents, Both Independently And Combined, From Increased Physical Activity And Sleep (Saunders Et Al., 2016). Both Physical Activity And Sleep Have Demonstrated Significant Inverse Associations With Depression, Even After Controlling For Age, Gender And Socioeconomic Backgrounds. The Current Study Has Demonstrated That Higher Volumes Of Physical Activity Were Positively Associated With More Hours Of Self-Reported Sleep And 
Higher Self-Reported Sleep Quality. A Previous Longitudinal Study Found That Depressive Symptoms, Physical Activity And Sleep Disturbances Were Significantly Interrelated Over Time With Initial Levels Of Depressive Symptoms Predicting Increases In Sleep Disturbance And Initial Levels Of Sleep Disturbance Predicting Decreases In Physical Activity (Raudsepp \& Vink, 2019). Two Main Hypotheses Have Been Suggested As To The Mechanisms Through Which Sleep Is Positively Impacted By Physical Activity. Higher Levels Of Activity May Produce Physiological Changes That Are Favourable To Sleep Regulation. An Experimental Trial In Young Adolescents Found That Exposure To High-Intensity Exercise Resulted In A Significant Rise In The Proportion Of Slow Wave Sleep, Greater Sleep Efficiency And Shorter Sleep Onset Latency (Dworak Et Al., 2008) While Another Trial In Older Adolescents Found Three Consecutive Weeks Of Morning Running Led To Increased Objective Measures Of Total Sleep And Decreased Objective Sleep Onset Latency (Kalak Et Al., 2012). The Second Hypothesis Suggests The Sleep-Promoting Effects Of Increased Physical Activity Are Mediated By Psychological Functioning (Biddle \& Mutrie, 2008), Such As Reduced Symptoms Of Anxiety, Depression And Stress Through Physical Activity (Dunn, Trivedi, Kampert, Clark \& Chambliss, 2005).

\section{Limitations}

While The Large Representative Sample Was A Strength Of The Study, The Use of Self-Report Measures Is A Limitation. Future Investigations Should Look To Include Objective Measures Of Physical Activity And Sleep In A Sub-Sample To Check For Validity Of Reporting. Previous Investigations Have However Shown That Adolescents With Higher Subjective And Objective Physical Activity Levels Are More Likely To Experience A Good Night's Sleep Subjectively And Objectively. It Must Be Noted That Studies Relating Physical Activity To Sleep Where Both Measures Were Assessed Subjectively Or Objectively Identified Larger Effect Sizes, Than Those Combining Subjective With Objective Measures. Data Collection For This Study Took Place In October Which May Also Have Had An Effect On Sleeping Patterns Due To The Shortening Of Daylight Hours. Also, It Must Be Acknowledged That An Observational Study Cannot Reliably Predict A Cause And Effect Relationship Between Sleep And Wellbeing. An Interventional Study Would Be Required To Show That Increasing Sleep Or Increasing Physical Activity Leads To Enhanced Wellbeing.

\section{Conclusion}

This Study Supports The Link Between Daily Physical Activity, Sleep And Mental Health Outcomes In A Sample Of Irish Adolescents. Sleep Was 
Found To Have A Significant Association With Positive And Negative Markers Of Mental Health In Adolescents. Mental Health Was Significantly Reduced With Less Sleep And Lower Quality Of Sleep. The Current Findings Suggest That 9-10 Hours Of Sleep Is The Optimal Amount For Both Enhanced Wellbeing And Reduced Symptoms Of Anxiety And Depression. Higher Volumes Of Physical Activity, And Engagement In More Sports, Were Significantly Associated With More And Better Sleep Which May Explain, In Part, The Positive Effect Physical Activity And Engagement In Sport Has On Mental Health And Wellbeing In Adolescents. The Results Of This Study Can Be Used To Support And Inform School And Community-Based Interventions With Aims To Employ Multicomponent Behaviour Modifications To Improve Multiple Health Markers That Have Positive Effects On Each Other.

\section{Acknowledgements}

The Authors Wish To Thank The Trial Participants, Whose Willingness To Take Part Made This Study Possible. The Authors Are Also Grateful To The Participating School For Facilitating Testing And Completion Of Questionnaires During School Time.

\section{References:}

1. Biddle, S. J., \& Mutrie, N. (2007). Psychology Of Physical Activity: Determinants, Well-Being And Interventions. Routledge.

2. Burns, R. D., Fu, Y., Brusseau, T. A., Clements-Nolle, K., \& Yang, W. (2018). Relationships Among Physical Activity, Sleep Duration, Diet, And Academic Achievement In A Sample Of Adolescents. Preventive Medicine Reports, 12, 71-74.

3. Buysse, D. J., Reynolds III, C. F., Monk, T. H., Berman, S. R., \& Kupfer, D. J. (1989). The Pittsburgh Sleep Quality Index: A New Instrument For Psychiatric Practice And Research. Psychiatry Research, 28(2), 193-213.

4. Carskadon, M. A., Acebo, C., \& Jenni, O. G. (2004). Regulation Of Adolescent Sleep. Ann NY Acad Sci, 1021, 276-291.

5. Dahl, R. E., \& Lewin, D. S. (2002). Pathways To Adolescent Health Sleep Regulation And Behavior. Journal Of Adolescent Health, 31(6), 175-184.

6. Dewald, J. F., Meijer, A. M., Oort, F. J., Kerkhof, G. A., \& Bögels, S. M. (2010). The Influence Of Sleep Quality, Sleep Duration And Sleepiness On School Performance In Children And Adolescents: A Meta-Analytic Review. Sleep Medicine Reviews, 14(3), 179-189.

7. Dooley, O’Connor, Fitzgerald \& O’Reilly, (2019). My World Survey II: National Study Of Youth Mental Health In Ireland. Jigsaw And UCD School Of Psychology. 
8. Dunn, A. L., Trivedi, M. H., Kampert, J. B., Clark, C. G., \& Chambliss, H. O. (2005). Exercise Treatment For Depression: Efficacy And Dose Response. American Journal Of Preventive Medicine, 28(1), 1-8.

9. Dworak, M., Wiater, A., Alfer, D., Stephan, E., Hollmann, W., \& Strüder, H. K. (2008). Increased Slow Wave Sleep And Reduced Stage 2 Sleep In Children Depending On Exercise Intensity. Sleep Medicine, 9(3), 266-272.

10. Foti, K. E., Eaton, D. K., Lowry, R., \& Mcknight-Ely, L. R. (2011). Sufficient Sleep, Physical Activity, And Sedentary Behaviors. American Journal Of Preventive Medicine, 41(6), 596-602.

11. Fredriksen, K., Rhodes, J., Reddy, R., \& Way, N. (2004). Sleepless In Chicago: Tracking The Effects Of Adolescent Sleep Loss During The Middle School Years. Child Development, 75(1), 84-95.

12. Gaina, A., Sekine, M., Hamanishi, S., Chen, X., Wang, H., Yamagami, T., \& Kagamimori, S. (2007). Daytime Sleepiness And Associated Factors In Japanese School Children. The Journal of Paediatrics, 151(5), 518-522.

13. Gangwisch, J. E., Babiss, L. A., Malaspina, D., Turner, B. J., Zammit, G. K., \& Posner, K. (2010). Earlier Parental Set Bedtimes As A Protective Factor Against Depression And Suicidal Ideation. Sleep, 33(1), 97-106.

14. Gariepy, G., Danna, S., Gobina, I., Rasmussen, M., De Matos, M. G., Tynjälä, J., ... \& Schnohr, C. (2020). How Are Adolescents Sleeping? Adolescent Sleep Patterns And Sociodemographic Differences In 24 European And North American Countries. Journal Of Adolescent Health, 66(6), S81-S88.

15. Giannotti, F., Cortesi, F., Sebastiani, T., \& Ottaviano, S. (2002). Circadian Preference, Sleep And Daytime Behaviour In Adolescence. Journal Of Sleep Research, 11(3), 191-199.

16. Gomez, R. L., Newman-Smith, K. C., Breslin, J. H., \& Bootzin, R. R. (2011). Learning, Memory, And Sleep In Children. Sleep Medicine Clinics, 6(1), 45-57.

17. Gradisar, M., Gardner, G., \& Dohnt, H. (2011). Recent Worldwide Sleep Patterns And Problems During Adolescence: A Review And Meta-Analysis Of Age, Region, And Sleep. Sleep Medicine, 12(2), 110-118.

18. Gregory, A. M., \& O'connor, T. G. (2002). Sleep Problems In Childhood: A Longitudinal Study Of Developmental Change And Association With Behavioral Problems. Journal of The American Academy Of Child \& Adolescent Psychiatry, 41(8), 964-971.

19. Hirshkowitz, M., Whiton, K., Albert, S. M., Alessi, C., Bruni, O., Doncarlos, L., ... \& Neubauer, D. N. (2015). National Sleep 
Foundation's Sleep Time Duration Recommendations: Methodology And Results Summary. Sleep Health, 1(1), 40-43.

20. Johnson, E. O., Roth, T., \& Breslau, N. (2006). The Association Of Insomnia With Anxiety Disorders And Depression: Exploration Of The Direction Of Risk. Journal Of Psychiatric Research, 40(8), 700708.

21. Kalak, N., Gerber, M., Kirov, R., Mikoteit, T., Yordanova, J., Pühse, U., ... \& Brand, S. (2012). Daily Morning Running For 3 Weeks Improved Sleep And Psychological Functioning In Healthy Adolescents Compared With Controls. Journal Of Adolescent Health, 51(6), 615-622.

22. Kaneita, Y., Yokoyama, E., Harano, S., Tamaki, T., Suzuki, H., Munezawa, T., ... \& Ohida, T. (2009). Associations Between Sleep Disturbance And Mental Health Status: A Longitudinal Study Of Japanese Junior High School Students. Sleep Medicine, 10(7), 780786.

23. Kenney, E. L., \& Gortmaker, S. L. (2017). United States Adolescents' Television, Computer, Videogame, Smartphone, And Tablet Use: Associations With Sugary Drinks, Sleep, Physical Activity, And Obesity. The Journal Of Pediatrics, 182, 144-149.

24. Keyes, K. M., Maslowsky, J., Hamilton, A., \& Schulenberg, J. (2015). The Great Sleep Recession: Changes In Sleep Duration Among US Adolescents, 1991-2012. Pediatrics, 135(3), 460-468.

25. Kredlow, M. A., Capozzoli, M. C., Hearon, B. A., Calkins, A. W., \& Otto, M. W. (2015). The Effects Of Physical Activity On Sleep: A Meta-Analytic Review. Journal Of Behavioral Medicine, 38(3), 427449.

26. Liu, X., Buysse, D. J., Gentzler, A. L., Kiss, E., Mayer, L., Kapornai, K., ... \& Kovacs, M. (2007). Insomnia And Hypersomnia Associated With Depressive Phenomenology And Comorbidity In Childhood Depression. Sleep, 30(1), 83-90.

27. Magee, C., Caputi, P., \& Iverson, D. (2014). Lack Of Sleep Could Increase Obesity In Children And Too Much Television Could Be Partly To Blame. Acta Paediatrica, 103(1), E27-E31.

28. Moore, P., Bardwell, W. A., Ancoli-Israel, S., \& Dimsdale, J. E. (2001). Association Between Polysomnographic Sleep Measures And Health-Related Quality Of Life In Obstructive Sleep Apnoea. Journal Of Sleep Research, 10(4), 303-308.

29. Murphy, J., Sweeney, M. R., \& Mcgrane, B. (2020). Physical Activity And Sports Participation In Irish Adolescents And Associations With Anxiety, Depression And Mental Wellbeing. Findings From The 
Physical Activity And Wellbeing (Paws) Study. Physical Activity And Health, 4(1).

30. Murphy, J., Mcgrane, B., \& Sweeney, M. R. (2021). Physical Activity, Mental Health And Wellbeing Of Irish Adolescents During Covid-19 Restrictions. A Re-Issue Of The Physical Activity And Wellbeing Study (PAWS). Physical Activity And Health, 5(1), Pp. 215-228.

31. Narmandakh, A., Oldehinkel, A. J., Masselink, M., De Jonge, P., \& Roest, A. M. (2021). Affect, Worry, And Sleep: Between-And WithinSubject Associations In A Diary Study. Journal Of Affective Disorders Reports, 100134.

32. Pyper, E., Harrington, D., \& Manson, H. (2017). Do Parents' Support Behaviours Predict Whether Or Not Their Children Get Sufficient Sleep? A Cross-Sectional Study. BMC Public Health, 17(1), 432.

33. Randler, C., Faßl, C., \& Kalb, N. (2017). From Lark To Owl: Developmental Changes In Morningness-Eveningness From NewBorns To Early Adulthood. Scientific Reports, 7, 45874.

34. Raniti, M. B., Waloszek, J. M., Schwartz, O., Allen, N. B., \& Trinder, J. (2018). Factor Structure And Psychometric Properties Of The Pittsburgh Sleep Quality Index In Community-Based Adolescents. Sleep, 41(6), Zsy066.

35. Raudsepp, L., \& Vink, K. (2019). Brief Report: Longitudinal Associations Between Physical Activity, Sleep Disturbance And Depressive Symptoms In Adolescent Girls. Journal of Adolescence, 72, 37-41.

36. Ryff, C. D., Singer, B. H., \& Dienberg Love, G. (2004). Positive Health: Connecting Well-Being With Biology. Philosophical Transactions Of The Royal Society Of London. Series B: Biological Sciences, 359(1449), 1383-1394.

37. Sadeh, A., Dahl, R. E., Shahar, G., \& Rosenblat-Stein, S. (2009). Sleep And The Transition To Adolescence: A Longitudinal Study. Sleep, 32(12), 1602-1609.

38. Saunders, T. J., Gray, C. E., Poitras, V. J., Chaput, J. P., Janssen, I., Katzmarzyk, P. T., ... \& Carson, V. (2016). Combinations Of Physical Activity, Sedentary Behaviour And Sleep: Relationships With Health Indicators In School-Aged Children And Youth. Applied Physiology, Nutrition, And Metabolism, 41(6), S283-S293.

39. Shochat, T., Cohen-Zion, M., \& Tzischinsky, O. (2014). Functional Consequences Of Inadequate Sleep In Adolescents: A Systematic Review. Sleep Medicine Reviews, 18(1), 75-87.

40. Spiegel, K., Tasali, E., Penev, P., \& Cauter, E. V. (2004). Brief Communication: Sleep Curtailment In Healthy Young Men Is Associated With Decreased Leptin Levels, Elevated Ghrelin Levels, 
And Increased Hunger And Appetite. Annals of Internal Medicine, 141(11), 846-850.

41. Steptoe, A., O'Donnell, K., Marmot, M., \& Wardle, J. (2008). Positive Affect, Psychological Well-Being, And Good Sleep. Journal Of Psychosomatic Research, 64(4), 409-415.

42. Stone, M. R., Stevens, D., \& Faulkner, G. E. (2013). Maintaining Recommended Sleep Throughout The Week Is Associated With Increased Physical Activity In Children. Preventive Medicine, 56(2), 112-117. 